\title{
Online citizen panels as an advance in research and consultation: A Review of pilot results
}

\section{Commonwealth Journal of Local Governance \\ Issue 6: July 2010 \\ http://epress.lib.uts.edu.au/ojs/index.php/cjlg}

\begin{abstract}
Anne Sharp
Katherine Anderson

Ehrenberg-Bass Institute for Marketing Science, University of South Australia
\end{abstract}
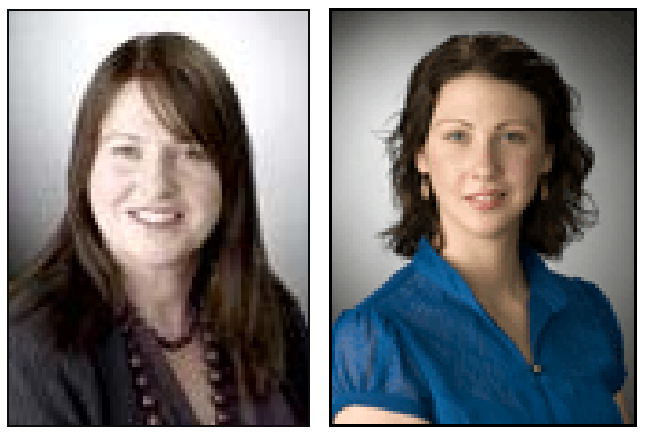

\begin{abstract}
This paper details a new model for local government consultation and research. The model involves a local government partnering with a university to establish an online panel of citizens that is then used for consultations and research on a range of local government issues over time. The model was evaluated across an 18-month pilot involving three metropolitan councils in South Australia, each running its own panel. This paper details the rationale behind the panels, steps involved in their establishment, and what the most effective recruitment methods were to build panel membership. The model's ability to recruit a wide audience of citizens as members, including those who would not normally participate in local government matters, is examined, as well as citizen expectations of the panel and satisfaction with being a member. Finally, key learnings from the pilot are identified. The pilot results demonstrate that such an online panel model can be used effectively in the local government context. The panels achieved citizen membership wider than that historically seen in local government consultation and research, and were sustainable in terms of continued participation and high levels of citizen satisfaction. Since the pilot, the project has grown to include seven councils and almost 2500 citizens. This is further evidence that this model offers a way forward for enhanced citizen participation in local government decision-making and policy development.
\end{abstract}

\section{Keywords}

Local Government, Research and Consultation, Community Consultation, Citizen Panel, Online. 


\section{Introduction}

Meaningful and effective community consultation and participation have been identified as critical for local government in the $21^{\text {st }}$ century, as has improved monitoring and evaluation of local government performance. Coupled with this, has been a call for local government to find new ways to build capacity with cited examples including partnering with other organisations (Sansom, 2010). This paper examines the pilot of a model for local government citizen consultation and research that goes some way to introducing these desired elements.

The pilot was initiated out of frustration with the limitations and expense associated with existing methods of citizen consultation and research. Two large metropolitan local governments in Adelaide, South Australia, approached and partnered with a University of South Australia-based research institute to trial an alternative approach to community consultation and research - an online citizen panel. Funding from the Local Government Association of South Australia supported an 18-month pilot of the model. The pilot saw three metropolitan city councils establishing online panels of citizens with which they regularly consulted and conducted research. Each panel sought wide membership from citizens living and working in the local government area and aimed to reach an initial critical mass of 300 members.

While many councils and other local government agencies conduct off-line research and consultations, these are rarely done through a continuous multiple-purpose panel, built specifically for that organisation. Rather, specialist advisory committees or citizen juries are used, made up of a small number of citizens for a particular purpose or issue. Such consultation mechanisms are common in the UK and increasingly so in Australia. As for the use of online methods, at the time the pilot was initiated, online research and consultation in the local government arena had mostly been limited to one-off research or consultation surveys hosted on council web sites on an ad hoc basis, and ongoing online citizen panels not been established. ${ }^{1}$ The pilot project examined in this paper was the first in Australia to establish online panels across multiple councils and with the aim of learning and disseminating knowledge about this approach. It was also the first example

\footnotetext{
1 Parramatta Council would be one notable exception to this. The authors would like to gratefully acknowledge the time and information shared by Parramatta Council (especially Wade Clark) during the project's development. Ku-ring-gai Council, north of Sydney, is another example of a council that has a multiple-use citizen panel, built specifically for its needs.
} 
of local governments partnering with an external organisation (in this case a universitybased research institute) to establish and manage the online citizens panels. The university had its own in-house research field team, including the ability to write, host and analyse consultation surveys. This partnership gave local government access to research design and consultation implementation expertise, as well as being able to assure panel members of anonymity and confidentiality in their participation. The university gained benefits from being able to build a research agenda around the pilot; one that was grounded in practice-oriented research.

\section{Research and consultation in the local government context}

\section{Consultation and research: An operating requirement}

Community consultation and research has become an essential aspect of local government operations. In Australia, like many other jurisdictions, local governments are required to inform, and often to consult with, their citizens on matters that potentially affect them. The exact requirements vary for different matters and are generally governed by state laws and each local government's consultation policy. For example, in South Australia, under the Local Government Act (1999), there is a statutory requirement for local councils to consult with citizens when establishing strategic plans, setting annual business plans and budgets, changing rating policies, or considering changes to the status of community land. In addition, there is a requirement to notify citizens of such activities and give 'interested persons' a 'reasonable opportunity' to have input into the planning process. This includes, at a minimum, the publication of notices in the local paper, making draft plans publicly available, and considering submissions from members of the public when drafting plans.

In addition to these requirements to consult citizens, there is increasing pressure for government policy to be informed by research, and for performance, service delivery and customer service to be monitored by undertaking research with citizens (UTS Centre for Local Government/LGCSA 2007). In the local government context, research generally refers to activities where the aim is to gather reliable, statistically projectable results, usually by surveying a sample that is representative of the local population. Community consultation, in contrast, is typically more focused on gathering input or feedback from those who are interested in contributing. At times, the two tasks of research and 
consultation can have very different, and potentially competing objectives, especially when consultation is undertaken as a socio-political task but research is conducted as an objective scientific process. Reconciling these can be a challenging task for local government managers.

However, whilst acknowledging that research and consultation are different activities with different principles and objectives, both can be considered forms of public participation. The International Association for Public Participation (IAP2) puts forward one of the most well known frameworks for categorising community participation. The IAP2 spectrum of participation ranges from 'informing the public', through to 'listening to the public', 'engaging in problem solving', and 'developing agreements' (for more information see HTTP://iap2.org/practionertools/index.shtml). According to the 'spectrum', the research and consultation examples discussed in this paper would mostly be classed as 'listening' and this paper evaluates the effectiveness of the online panel approach for this task.

\section{Consultation and research: $A$ valued activity}

Citizen consultation and research are valued means of obtaining feedback and input from the community, enabling councils to be more responsive and representative in their decision-making (City of Tea Tree Gully 2001). They are also seen as means by which to build social capital, through encouragement of broader understanding and ownership of decisions and plans (Aukett 2009) and to enhance a council's reputation as open, accountable and willing to listen (Local Government Association of SA 2007).

Over the last forty years, the value of engaging citizens in decision-making and governance has been discussed extensively in the planning, public administration and governance literature (see Day 1997, Bishop and Davis 2002, or Irvin and Stansbury 2004 for comprehensive reviews). There has been a particular focus on the potential of citizen participation to improve outcomes and foster good governance. Community consultation is seen as one of the central mechanisms to raise the level of citizen participation in decision-making and engage constituents (Brackertz and Meredyth, 2009), and the last decade has seen a groundswell of support for the concept of community input in local government. This support has been manifest in the appointment of 'community engagement officers' and the institution of 'consultation 
policies' which outline the range of issues on which local governments will seek input, the principles guiding processes, and appropriate methods to be used (see Brackertz and Meredyth, 2009 and Local Government Association of South Australia 2007 for reviews of policies and practices in various Australian states). Increased consultation and research with citizens are part of this broader trend towards greater community engagement and collaboration (Lowndes, Pratchett et al. 2001). Local government is moving away from using consultation activities as a 'disaster check' towards actively seeking citizen input early in decision-making and policy development processes, and most councils in Australia now use a diverse range of methods and approaches for working with citizens (Hornby 2007).

In the context of local government, research amongst citizens is valued for its ability to monitor and provide reliable feedback to local governments regarding service delivery. It is also relied upon to provide local government with a representative snapshot of community sentiments on an issue or decision, often when there have been vocal objections from a section of the community, or where an impasse has been reached.

The literature does not often acknowledge the challenges managers face in translating principles of consultation and research into activities, and how difficult, time consuming, and costly consultation and research can be for a local government to implement. Many local governments face capacity issues and do not have the staff or infrastructure to design or implement consultation strategies themselves (Lowndes, Pratchett et al. 2001). For these reasons, many local governments choose to outsource the design or implementation of research or consultation to external providers, making activities costly and preventing local governments from learning how to do these things well themselves. For many, the purported benefits of citizen consultation and research fall short in reality.

\section{Consultation and research: $A$ frustrating reality}

Local governments face a challenging and frustrating reality when it comes to putting consultation policies into practice. The results of consultation activities are often disappointing, both in terms of the number of people engaged and the usefulness of the findings for developing policies or aiding decision-making (Cuthill 2001). Moreover, local governments often find consultation activities difficult to sustain over the longer term, typically running very effective consultations on just one or two issues (usually due 
to the dedication of key staff to the process), but lacking the resources, staff, or time to do so on a sustained basis.

As Brackertz and Meredyth (2009) point out, the process used to facilitate community participation largely determines the outcomes. A range of different processes or approaches are commonly used in local government (see Heylen 2007 for a discussion of Australian practices or Lowndes, Pratchett et al. 2001 for a discussion of practices in UK councils), all of which have limitations or challenges. For example, 'town hall' meetings and public submission processes usually garner extremely limited participation and attract mostly people who are highly involved with the issue under consideration and are polarised in their opinions. This is because attending a meeting or writing a submission requires citizens to go to considerable effort, and consequently there is a large element of self-selection bias. The handfuls of people who do participate in such processes are usually part of a vocal minority opposed to a decision or policy and are therefore not representative of community sentiment. This is problematic for local governments, as they must make decisions that take into account the views of the entire community. This pattern of small numbers of unrepresentative, often negative participants can be disillusioning to local government staff and decision-makers. There is scepticism amongst managers that consultation will garner any genuinely new ideas or useful feedback or that it will amount to anything more than just the 'usual suspects' (Brackertz and Meredyth 2009). Similarly, surveys designed by councils and distributed to community groups or through service contact points are often criticised for being poorly designed, not being sufficiently impartial, and for achieving only small, unrepresentative samples. As a result, local government decision-makers tend to be dismissive or distrusting of findings gathered through such processes (Wilson 1999).

A more proactive approach, aimed at overcoming the problem of representativeness in consultation, is recruiting groups of citizens willing to be consulted on a range of issues, rather than recruiting interested citizens on an ad hoc basis to be consulted on a single issue. Citizen Advisory Panels are generally set up in this way (Lowndes, Pratchett et al. 2001), with a select panel being recruited to represent the community and meeting regularly to review policy and advise council on a range of issues. However, the chance of these few selected individuals being truly representative is slim, especially given that the nature of the advisory process (regular meetings) is likely to attract only politically 
engaged citizens. Citizens' Juries tend to be better in terms of representativeness because participants are typically selected through random sampling approaches (Hendricks 2002), but require substantial resources to set up. Managers often lack the skills or infrastructure to do so independently, managing them can be time consuming, and they too typically only involve a few individuals.

Larger government agencies commonly use telephone and mail survey methods to garner the opinions of a broad cross-section of the community, and often engage external organisations to implement it to overcome design, implementation and impartiality issues. However the time and expense of such methods is an impediment to using them regularly or for many issues. Even a large city council can only afford to do two or three such research exercises a year, leaving many decisions under-informed with respect to the views of the community.

There is a clear gap between what local governments would like to achieve in terms of citizen consultation and research, and current practice, suggesting a need for innovative approaches and new models which overcome time, resource and competency constraints.

\section{Online approaches}

An emerging methodology for consultation and research is online. The recent growth in Internet connectivity means that in most countries a majority of the population can be reached online - in Australia, $72 \%$ of the population is using the internet regularly (Australian Bureau of Statistics 2009). One of the key advantages of using an online approach is that it is easier for citizens to participate. People can choose to participate whenever and wherever is convenient for them. It is far easier for people to participate in an online survey or comment on a forum than to attend a public meeting or write a formal submission. It is also less threatening as people can participate in private, take as much time as they need, and can choose to remain anonymous, making full disclosure more likely (Holbrook and Krosnick 2010). By making consultation and research processes more accessible to the public, more people should be willing to participate and potentially, participants may also come from a more diverse cross-section of the community. 
Some local governments, both in Australia and other Commonwealth countries, are already using online approaches. Surveys or forums are most commonly used and are generally focused on a single issue and hosted on the agency's website. However, such approaches have limitations in that presumably only those people who are already engaged with local government affairs or the particular issue tend to notice them and go to the effort of visiting the website and participating. So while the process may be more accessible and involve more people, the issues of representativeness and involving the silent majority are not really addressed by hosting an online survey on a website.

A more promising approach is to establish a panel of citizens who are interested in being consulted on a range of issues to do with their local community and inviting them more directly to participate in consultations online. A panel that is recruited to provide feedback on a range of issues will likely be less affected by issue-based non-response bias, and more able to represent a community accurately than a sample of respondents self-selected themselves to participate in a consultation on a single issue. If the panel is to be predominantly based online then citizens may be willing to join as participating will be easy and convenient for them.

Online panels are widely used by private sector companies and academics to conduct research and have been shown to have advantages over telephone and mail surveys in terms of their ability to collect a large number of responses relatively quickly and at a low incremental cost (see Ilieva, Baron et al. 2002 for a particularly good summary of their advantages). Many research and consumer-orientated companies have been successful in establishing large online panels of their customers and using them for research (Batinic and Morser 2005 as cited in Joinson, McKenna et al. 2007).

Online panels could be a very promising alternative for local governments wanting to conduct research and consult with their community. There have been some ad hoc moves towards this approach in Australia. As noted earlier, at the time of the pilot at least two local governments in Australia had successfully recruited and used citizen panels on an ongoing basis, although online components were minimal. Moreover, online panels had not been implemented in a co-ordinated way across multiple agencies, nor had they been subject to academic scrutiny. The approach also had not been run in a partnership context between an agency and a research partner. These were some of the motivations behind the pilot project when launched in late 2007. 


\section{The online panel model in action}

The online panel model was piloted in three metropolitan councils in South Australia. The councils publicised widely to their local communities that they were establishing an online panel and were looking for citizens to be involved. They used a variety of promotional methods, the effectiveness of which is reported later in this paper. The panels were promoted as a way that citizens could 'help shape their city's future' and that, once registered, people would be invited (via email) to participate in between four to eight online surveys a year for their local council. The registration process was relatively simple. The university designed and managed an online survey to collect names, contact details, demographic variables relevant to the local government context (household composition for example) and information about their prior contact, involvement and satisfaction with their local government. These variables were used to evaluate the representativeness of the panels. It was felt that a simple demographic comparison against the Australian Bureau of Statistics profile of the local government area would not address of issue of representativeness in terms of attitudes, knowledge and involvement in the sorts of issues to be discussed. So, this fuller range of variables was collected on registration and used in the representativeness analyses. All of this information was fed into a database designed by the university to manage responses and facilitate the sending of surveys.

Councils notionally aimed to recruit 300 panel members, as this is in the vicinity of what a commercial research activity would aim to sample. Once panels reached 300 they were validated against a traditionally used research methodology (telephone interviews or mail surveys) by running the same survey in parallel through both methodologies and directly comparing results across demographic, attitudinal and behavioural variables. Results were also validated against Australian Bureau of Statistics data for each area. If deemed to be sufficiently representative by the academic researchers at the completion of this process (all panels met this requirement), the panel was then used for research and consultation. Even once their panels reached 300 the councils continued to publicise them and recruited additional members throughout the pilot period.

An important element of these panels was that anyone living, working, using services, or paying rates in the local government area was welcome to join their local panel. Members were not selected and membership was not restricted in any way. 
Correspondingly, tests for representativeness were aimed at establishing the validity of the online approach and the panels, rather than obtaining a perfectly matched sample. The principle of open membership is an important distinction from panels where members are selected on the basis of their credentials or characteristics, or where demographic or geographic quotas are imposed. Open membership was adopted to signal the councils' openness to community input from wherever it came. Furthermore, because the panels were also promoted as an exercise in community engagement by the councils, turning interested citizens away would have been counter-productive.

That the panels were to be predominantly engaged online was also a key concern for councils, and strategies were implemented to make the panels more accessible: making the online surveys available through local library computers, running training sessions for citizens not familiar with email or online surveys, and in some cases, making paper versions of the survey available to those citizens without access to a computer. Interestingly, these paper surveys had extremely low uptake. From this, it appears that online access was not an impediment to participation and that people did have a preference for the convenience of the online option.

The panels were managed by the university partner, protecting the anonymity of participants, enabling the sharing of database and survey infrastructure costs and overcoming issues of capacity and expertise within councils. The university also designed the surveys used for consultations and research, managed the online surveys, conducted analysis and reported back survey findings to council managers and elected representatives. This enabled councils without the skills or capacity to do so themselves to establish panels and was important to the integrity of the process. Community participants were able to comment honestly, knowing that the university, not the council, managed survey responses and that their identity would remain anonymous. The involvement of the university as an external gatekeeper partner also has implications for improved willingness of citizens to join a panel in the first place (Heberlein and Baumgartner 1978). That consultation surveys were designed and analysed by an external agency gave credibility and independence to the process and ensured councils saw the panels as reliable sources of information. The university also acted as the custodian of the panels, advocating on their behalf and ensuring they were not over- or under-utilised, a role that was important for the long-term health of the panels. Because 
of the university's academic interest in the panels and its full in-house research services ability, resources were available to experiment and provide valued-added services (eg the use of pop-ups in surveys) to the panels that would have been prohibitively expensive and not offered in as flexible a way if a commercial research partner had been involved.

Each council conducted between five and seven research or consultation surveys over the course of the 18-month pilot. Consultations were scheduled every three months (approximately), or conducted as need arose. The frequency of consultation was one of the issues on which feedback from panel participants was sought at the completion of the pilot. Council managers and elected members determined what issues were put to the panels and the council retained ownership of the panel. Although all communications were sent via the university's software and servers, everything was branded as being an initiative of the individual council in collaboration with the university partner and as part of a broader cross-council program ('Community Panel'), giving consistency to the process.

\section{Evaluating the online panel model}

Through the pilot the feasibility and sustainability of an online panel model was tested in the local government context. The most effective recruitment methods were determined and the time it took to build a panel of a size sufficient for research and consultation established empirically. Participant data was analysed to determine if the panels were able to engage citizens who had not previously participated in community consultations, and whether community participants were satisfied with the model. The results from this evaluation are discussed below.

\section{Results: Panel membership numbers}

A key question for the pilot was whether the local councils could recruit a panel of sufficient size for conducting research and consultation. Table 1 details the number of panel members each council had recruited by the end of the 18-month pilot. 
Table 1: Panel membership numbers

\begin{tabular}{c|c|c|c}
\hline Local Council & Panel Members & $\begin{array}{c}\text { Area Population } \\
\text { (ABS Census 2006) }\end{array}$ & $\begin{array}{c}\text { Panel as \% of } \\
\text { Population }\end{array}$ \\
\hline A & 732 & 42000 & 1.8 \\
B & 684 & 95000 & 0.7 \\
C & 437 & 45000 & 1.0 \\
\hline
\end{tabular}

As the results illustrate, each of the local governments exceeded the notional 300member 'threshold' by the close of the pilot, recruiting between 400 and 700 members each. Although the local governments varied in population from 42000 to 95000 residents, each panel represented about one percent of the local government's residential population. Whilst this may seem too few to be considered effective representation, it is a vast improvement on public meetings that typically engage fewer than 50 participants, or even commissioned phone surveys that typically include only 300 to 400 participants. Hence, the participating councils judged the panels a success in terms of their ability to engage more citizens than traditional approaches.

How long it took councils to build their panel to the 'threshold' size of 300 members varied from as little as four months to just over six months. Council B had more than 500 members within five months; however, Council A recruited just 262 members in the same time period. A controversial local issue then saw an additional 150 people join that panel in a single week, growing the panel to 416 members after six months of recruitment. This raises the issue of the potential for a particular issue to skew a panel which, while not empirically examined in this paper, is important. Council C grew to 400 members within four months and then remained stable for the remainder of the pilot. On the basis of these results, it seems that local governments can build a usable citizen panel quite quickly - most certainly within six months of establishment.

\section{Results: Recruitment methods}

The pilot trialled a range of recruitment methods in order to evaluate their effectiveness in growing panel membership. The effectiveness of recruitment methods was captured through a (prompted) question in the registration survey asking new members how they heard about the panel. As the trends were the same across all three panels, the results are aggregated and are shown in Table 2. The total number of panel members reported in 
Table 2 is less than the number of panel members overall, as only the top five methods are listed.

Table 2: Top 5 recruitment methods

\begin{tabular}{l|c|c}
\hline \multicolumn{1}{c|}{ Recruitment Methods } & $\mathrm{n}$ & $\%$ \\
\hline Flyer with rates notice & 794 & 43 \\
Advert in council newsletter & 314 & 17 \\
Article in the local newspaper & 200 & 11 \\
Promotion on council website & 131 & 7 \\
Flyer at the library/ council offices & 126 & 7 \\
\hline
\end{tabular}

Recruitment methods with very broad reach, like a sending a flier to all ratepayers with the council's quarterly rates notices, were found to be most effective. Advertisements in council newsletters or articles in the local paper were the next most effective methods, primarily because they are circulated to every business and household. Other somewhat effective methods included promoting the panel on the council's website, at the council offices and library, and encouraging members to tell their friends. As these methods are fairly low cost to implement, they are probably worthwhile, although they recruit proportionally fewer members. Interestingly, recruitment methods that entailed additional resources or management time, like having staff hand out fliers at local events, tended not to result in much membership growth (less than three percent in total). That many of the most effective recruitment methods were 'off-line' is particularly notable and is likely to be important for the representativeness of such online panels.

\section{Results: Engaging the 'silent majority'}

Another research question for the pilot was whether an online panel approach could engage more than just the 'usual suspects' and effectively reach a wider audience of citizens. For this reason, two of the panels (A and B) were surveyed about their prior engagement with council and asked if they had previously attended a council meeting (and if so, how recently) or participated in any council consultations previously (no timeframe was set). Response rates were high, although not 100\%, with 330 members of Panel A and 353 members of Panel B completing these survey questions, the results of which are reported below in Tables 3 and 4 . 
Table 3: Panel participants - attendance at council meetings

\begin{tabular}{l|c|c}
\hline & $\begin{array}{c}\text { Panel A } \\
\%\end{array}$ & $\begin{array}{c}\text { Panel B } \\
\%\end{array}$ \\
\hline Never attended a council meeting & 62 & 68 \\
More than 12 months ago & 28 & 26 \\
Recently (in last 12 months) & 9 & 5 \\
Unsure & 1 & 1 \\
\hline Total & 100 & 100 \\
\hline
\end{tabular}

Table 4: Panel participants - previous participation in council consultations

\begin{tabular}{l|c|c}
\hline & Panel A & Panel B \\
& $\%$ & 72 \\
No, never participated before & 63 & 16 \\
Yes, have participated in the past & 28 & 12 \\
Unsure & 9 & 100 \\
\hline Total & 100 &
\end{tabular}

As the results in Tables 2 and 3 illustrate, the online citizen panels were able to engage people who had never been involved with their council before. Almost seven in 10 panel members had never attended a council meeting and most of the almost three in 10 who had, had done so more than a year before. Most panel members had not participated in local government consultations in the past either, suggesting the panels were reaching a new audience and engaging those citizens who had been silent. It is important to note that both of these councils had been proactive in their approaches to community consultation, running major community-wide consultation processes in the years preceding, so the results in Table 3 do not reflect a lack of effort on the part of councils, but rather the genuine difficulty in engaging the community.

Qualitative feedback from panel members supports the conclusion that online panels can effectively engage a new audience of constituents who have not participated in local government consultations before, and confirms the limitations with traditional approaches. The following quotes come from panel members via the survey seeking their feedback on the online panel model: 
A good way to have a say. I am usually quiet and do not have an opportunity to say what I think in a big group of people.

I've never previously felt I have a real voice in the council because my only option has been to go to council meetings. I prefer to comment in my own time after having considered a summary of issues.

I'm in favour of doing this on-line, means I actually get a chance to participate, which I wouldn't if I had to go into council or attend a meeting.

\section{Results: Consultation and research activities}

During the course of the pilot, 18 consultations or research activities were undertaken across the three council panels in the form of short online surveys. The topic of each survey is detailed in Table 5 in chronological order according to council. The response rate for each survey is also listed, along with the number of panel members at the time of the survey's launch. Multiplying the response rate and the number of panel members gives an approximation of the number of participants in each survey, but is not exact as new members continued to join during each survey period. In each instance, an email was sent to all registered panel members, inviting them to participate in the survey by visiting a linked website, and a reminder email was sent a few days later to any panel member who had not yet completed the survey.

Table 5: Topics and response rates

\begin{tabular}{c|l|c|c}
\hline $\begin{array}{c}\text { Local } \\
\text { Pov } \\
\text { Panel }\end{array}$ & Topic (in chronological order) & $\begin{array}{c}\text { Starting } \\
\text { Members } \\
n\end{array}$ & $\begin{array}{c}\text { Response } \\
\text { Rate } \\
\%\end{array}$ \\
\hline A & Consultation Preferences & 193 & 72 \\
A & Strategic Plan & 216 & 81 \\
A & Facilities & 539 & 84 \\
A & Service Quality \& Performance & 598 & 70 \\
A & Panel Participant Satisfaction & 682 & 58 \\
A & Council asset & 744 & 58 \\
A & Annual Business Plan \& Budget & 755 & 40 \\
\hline B & Annual Community Survey & 302 & 86 \\
B & Library Services & 608 & 74 \\
B & Community Art Show Standards & 609 & 60 \\
B & Annual Community Survey & 634 & 70 \\
B & Panel Participant Satisfaction & 617 & 55 \\
B & Annual Business Plan \& Budget & 684 & 50 \\
\hline
\end{tabular}




\begin{tabular}{l|l|l|l}
\hline C & Council Performance & 259 & 88 \\
C & Environmental Initiatives & 418 & 69 \\
C & Council Communications & 428 & 61 \\
C & Annual Business Plan \& Budget & 439 & 50 \\
C & Strategic Plan \& Environment Initiatives & 447 & 51 \\
\hline & Average & 513 & 66 \\
\hline
\end{tabular}

As Table 5 illustrates, the online panels were used successfully to conduct research and consultations on a wide range of topics - from service quality evaluations to strategic and annual business plans, council facilities and environmental initiatives. All of these surveys were used to collect qualitative and quantitative information that was then reported back to council.

Response rates for these surveys were generally high; the average response rate of $66 \%$ far exceeds the response rates reported in the literature for online surveys with email notification (see Ilieva, Baron et al. 2002 for a meta-analysis). These response rates were calculated controlling for bounce-backs to each survey (as these respondents never saw the invitation to participate). The number of bounce-backs was low, on average $4 \%$ for any given survey. The consistently high response rates also demonstrate that an online panel approach can garner enough responses to provide councils with a diversity of opinion on any given topic. And ensuring high response rates was a key focus; the university partner did not want non-response bias to undermine the representativeness or usefulness of the panels. The response rates were achieved by following best practices in online survey research such as pre-notification and reminder emails, personalised invitations, incentives for participation, and simple survey designs (see Mehta and Sivadas 1995 or Dillman, Tortora and Bowker 1998 for further discussion of design principles).

Response rates did vary for different survey topics, probably because some topics were seen as less salient to citizens (the impact of topic salience on response rates is firmly established by researchers such as Martin 1994). Across all three panels, response rates appear to fall over time. This may be related to the appeal of consultation topics: the lowest response rates were recorded for annual council business plan consultations and surveys where panel members were asked about their satisfaction with the panel process. 
These are surveys that may have been less interesting or relevant to panel members (the satisfaction survey being seen not to relate to council issues but rather the university's research agenda on methodology development). The fall in response rates may also be a consequence of the panels ageing and some members becoming 'inactive' or 'worn-out', but this hypothesis requires further investigation.

Surveys were usually available to panel members (and the wider public, provided they registered as a new panel member first) for between seven and ten days, although one consultation survey (Art Show Standards) was left open for just four days. When the panels were initially established, it was thought that a consultation period this long was necessary to ensure that all panel members had sufficient time to access the surveys and respond. However, it was found through the pilot that approximately $60 \%$ of those who participated in a survey did so in the first 48 hours after it was opened and participation rates only increased once reminders were sent (Reynolds, Sharp and Anderson 2009). On the basis of this evidence, a survey period of four days may be sufficient if a reminder email is sent on the third or fourth day to those panel members who have not participated.

Incentives, such as movie passes and gift vouchers, were offered by some councils for some surveys to encourage participation, but the effect on response rates was not clear. Additional evidence from the pilot suggests that providing feedback on the survey results and outcomes has a greater impact on participant motivation and survey response rates, at least over the long term.

\section{Results: Satisfaction of participants}

The purpose of the pilot was to evaluate the online panel model from all perspectives, including that of citizen participants. At the close of the pilot, participants from two panels were surveyed to see how satisfied they were with the model and the initiative. Almost 700 panel members participated in this survey and over $85 \%$ indicated they were 'satisfied' with the panel experience overall. The mean average rating was 8.6 on an 11point satisfaction scale where ' 0 ' denoted 'not at all satisfied' and '10' 'completely satisfied'. The comments received also demonstrate participants' satisfaction with the online panel model: 
This is a great way of being able to provide feedback to council at a time that is convenient.

I believe that the council has already gleaned important information through this forum. It is an excellent medium for honest feedback.

It is very important to gain community feedback. Online surveys are a simple and effective method.

Enjoy the opportunity to express my views and keep local government 'local'.

Furthermore, $60 \%$ of those who responded indicated that participating in the online citizen panel had improved their perceptions of their council. It seemed particularly effective in mitigating feelings of mistrust in council decision-making.

I've been involved in community affairs in [Council B] for several years and have been a constant critic of the lack of transparency in the way they do business and the priorities they give various issues. This seemed like a positive way to perhaps have some input into the process.

An interesting finding from the model evaluation by panel members was just how important hearing about the results and outcomes of consultations was for motivating them and keeping them engaged. It suggests a need for regular communications back to the panel regarding the results of consultation and research surveys and how council uses them. In the pilot, the feedback mechanism was regular newsletters, emailed to online panel members four times a year (usually after a survey), as well as updates on the respective council websites about the activities of the online panel. While it was not difficult to report back on survey findings, articulating how citizen input had influenced outcomes or decisions of council was more difficult, particularly when there was a long time lag between the survey and the decision.

During the model evaluation, panel members were also asked how frequently they would like to be asked to participate in research and consultation online. Almost two-thirds indicated they would like to participate in a consultation at least once a month, and around a third indicated they would like to participate every few months. Throughout the pilot, the councils conducted consultations less frequently than this, but there was no evidence in the panel member feedback that this adversely affected the quality of consultations or satisfaction of panel members. These results suggest scope to consult quite frequently with citizens through an online panel if a council so wishes. Consulting with the community as frequently as once a month would require local governments to 
think about the range of issues they consult the community on, as well as how they structure consultations and spread them throughout the year. For example, rather than just conducting a major consultation, a council could collect ideas for new projects or initiatives before it begins the process of drafting the budget, then seek input from the panel to prioritise the proposed projects, before finally seeking feedback on the allocations of budget. In this way a council could build up a picture of what the community wants over time and demonstrate directly back to the community how their feedback is (or is not, as the case may be) shaping the council's plans. Indeed, the feedback received in the pilot was that citizens prefer this more iterative approach to research and consultation. Panel participants do not just want to endorse or provide feedback on already formulated plans. The practical advantage of an iterative approach is that each consultation survey only has a few questions and is thus kept to a manageable length for participants.

\section{Conclusions and key learnings}

The overall conclusion from the pilot is that online citizen panels are a viable alternative to traditional methods of community consultation and research. Local governments can build online citizen panels of sufficient size to conduct research and consultation in a relatively short timeframe, using straightforward, cost-effective methods of recruitment. Online panels can effectively engage a new audience, satisfy community participants and improve citizens' perceptions of local governments. Once established, the online citizen panels can be used to conduct research and consultations on different topics, collecting qualitative and quantitative information useful for local government decision-making, and in a timely manner. Online panels have definite advantages for local government in terms of their ability to engage large numbers of citizens over an extended period of time, in a fairly cost-effective way.

All of the topics on which councils typically conduct research or consult the community can be handled through online surveys, although it may require outside expertise to do so. Certainly the university faced a significant challenge in developing online surveys that were both appealing and accessible to citizens on topics like annual business plans and budgets, as these were topics that had only been explored in a face-to-face context in the past. 
The pilot also demonstrated the value of a coordinated approach involving multiple councils. Local governments tend to conduct consultations and research surveys on similar topics, providing scope for them to compare approaches, share learnings and benchmark results. And this certainly occurred, but more so after the pilot, as networks between the council members strengthened and the feeling of being part of a community of councils was developed.

The online approach is, however, not without challenges. One of the main challenges was gaining internal council support for the model. Elected members were concerned about the potential for special interest groups to 'hijack' the process, whilst council managers worried that elected members might try to influence the outcomes by 'stacking' panels with their supporters. Both were nervous whether citizens, particularly older ones, would be interested in engaging with their local council online, on a sustained basis. However, the sheer number of citizens who participated, the eagerness of all residents (including older ones) to engage in this way, and continuous growth of the panels over time assuaged these fears. In the course of the 18-month pilot, there was only one instance with one panel in which 150 people joined in the wake of a controversial issue. However, the panel approach meant that these people were easy to identify and track over time. The objections outlined above were overcome by having senior managers willing to act as strong internal advocates for the model at each council. These managers educated their colleagues, secured access to elected members and advocated for the panels. Once the panels were established, these senior managers played a key role in planning the council's use of the panel and working with other managers to design and coordinate consultations.

Once established, the panels were another 'tool' or mechanism available to council managers and elected members for conducting public consultations, and provided another way for citizens to have a say on issues important to them and their way of life. The ability to collect a representative snapshot of community sentiment on issues in a timely manner was seen as a key benefit of an online panel approach. Whilst the panels did not replace all of a council's consultation and research activities, by the completion of the pilot they had been adopted by all three as the main method for doing so. 
Significantly, each participating local government saw its citizen panel purely as a 'consultative' mechanism. They used their panels to seek input or feedback from the community, listening and incorporating it into their planning and decision-making, but responsibility for decisions still rested with council managers and elected members. Communicating this option clearly to councils at the outset of the project was fundamental to obtaining their support for the pilot, and communicating this intended role of the panels to the public was important in managing community expectations. Whilst the citizen panels could have been used collaboratively or empowered with decision-making authority, a consultative role fitted best with the current needs and structure of the councils, and with the place the activities were seen to sit on the IAP2 participation spectrum. Giving the panels a consultative role did not threaten the authority of elected members because they were free to decide how much weight to give to feedback from their panel, and were able to act against the sentiments of the panel if they saw good reason. Whilst some might dismiss the process as tokenistic, feedback indicates that the local communities involved are satisfied with a consultative role for the panels. Certainly most citizen engagement takes the form of consultation (Bishop and Davis 2002), and this is the role where citizen panels are likely to gain the most traction, so it is valuable to understand how effective they are in this role.

Since the pilot ended in May 2009, the project has grown to include seven city councils across metropolitan South Australia and to engage almost 2500 citizens. The councils and the university continue to work in partnership, sharing learnings and developing the model further. Further information about how the project is progressing is available at http://www.communitypanel.com.au

\section{References}

South Australia Local Government Act 1999.

Aukett, T. (2009) Community Consultation and Engagement Procedure. Adelaide, City of Holdfast Bay: 1-4.

Australian Bureau of Statistics (2009) Household use of information technology, Australia, 200809. Canberra, Australian Bureau of Statistics: 1-3.

Bishop, P. and G. Davis. (2002) 'Mapping public participation in policy choices', Australian Journal of Public Administration 61(1): 14-29.

Brackertz, N. \& Meredyth, D. (2009) 'Community Consultation in Victorian Local Government: A Case of Mixing Metaphors?', Australian Journal of Public Administration 68(2), pp. 152-166

City of Tea Tree Gully. (2001) Public Consultation Policy. C4/25. Adelaide. 21294: 1-3. 
Cuthill, M. (2001). 'Developing local government policy and processes for community consultation and participation.' Urban Policy and Research 19(2): 183 - 202.

Day, D. (1997) 'Citizen Participation in the Planning Process: An Essentially Contested Concept?' Journal of Planning Literature 11(3): 421-434.

Heberlein, T., Baumgartner, R. (1978) 'Factors Affecting Response Rates to Mailed Questionaires: A Quantitative Analysis of the Published Literature.' American Sociological Review 43(4): 447-462

Hendriks, C. (2002) 'Institutions of deliberative democratic processes and interest groups: roles, tensions and incentives.' Australian Journal of Public Administration 61(1): 64-75.

Holbrook, A. L. and J. A. Krosnick (2010) 'Measuring Voter Turnout By Using The Randomized Response Technique: Evidence Calling Into Question The Method's Validity, doi: 10.1093/poq/nfq012.' Public Opinion Quarterly: 1-16.

Ilieva, J., S. Baron, et al. (2002) 'Online surveys in marketing research: pros and cons', International Journal of Marketing Research 44(3): 361-376.

Irvin, R., Stansbury, J. (2004) 'Citizen Participation in Decision Making: Is It Worth the Effort?' Public Administration Review 64:1: 55-65

Joinson, A. N., K. McKenna et al. (Eds.) 2007 The Oxford Handbook of Internet Psychology. Oxford, Oxford University Press.

Local Government Association of SA (2007) Community engagement showcase: leading practice examples in local government in South Australia. Adelaide, Government of South Australia: 1-38.

Lowndes, V., L. Pratchett, et al. (2001) 'Trends In Public Participation: Part 1 - Local Government Perspectives.' Public Administration 79(1): 205-222.

Margaret Heylen Consulting 2007 Community engagement snapshot of councils. Adelaide, Local Government Association of SA: 1-8.

Martin, C. L. (1994) 'The impact of topic interest on mail survey response behavior.' Journal of the Market Research Society 36(4): 327-337.

Reynolds, S., Sharp, A. \& Anderson, K. 2009 'Online surveys: response timeliness and issues of design.' 2009 Australian and New Zealand Marketing Academy Conference (ANZMAC), Melbourne.

Sansom, G. 2010 Editorial, Commonwealth Journal of Local Governance, 5 (March), 5-10

UTS Centre for Local Government/LGCSA 2007 'Just Communities: A National Network of Councils Promoting Community Wellbeing through Local Democracy', Project outline, University of Technology, Sydney.

Wilson, D. (1999) 'Exploring the limits of public participation in local government.' Parliamentary Affairs 52(2): 246-259. 